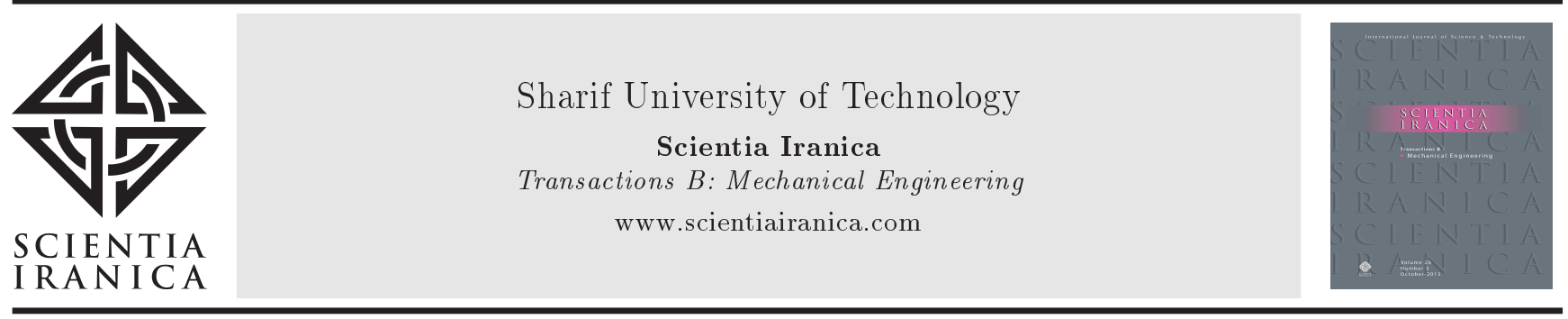

Research Note

\title{
Investigation of the effects of the weld groove shape on the residual stress formation in the butt-welded plates
}

\author{
M. Farahani ${ }^{a, *}$, S. Hakkak Zargar ${ }^{a}$ and D. Akbari ${ }^{b}$ \\ a. School of Mechanical Engineering, College of Engineering, University of Tehran, Tehran, P.O. Box 1439957131, Iran. \\ b. Department of Mechanical Engineering, Tarbiat Modarres University, Tehran, Iran. \\ Received 24 June 2014; received in revised form 1 June 2015; accepted 14 December 2015
}

\section{KEYWORDS \\ Remained stresses; \\ Finite element \\ technique; \\ Butt-welded plate; \\ Groove shape.}

\begin{abstract}
In this investigation, finite element technique and experimental method were utilized for analyzing the residual stresses created during the welding process of plates. In this way, a welded specimen was prepared with controlled welding parameters. Hole drilling technique was used to measure the residual stresses in some points of the welded specimen. To evaluate accuracy of the FE modeling, a comparison between experimental data and FE results was utilized and showed a good agreement. According to this study, the procedure of the FE modeling with acceptable accuracy was extended. This improved model was employed to investigate the influence of the groove shape on the remained stresses of welded plates. It was shown that the weld groove shape can affect the distribution of the remained stresses in thick welded plates, but it had no significant effect on peak stresses.
\end{abstract}

(C) 2016 Sharif University of Technology. All rights reserved.

\section{Introduction}

Residual or remained stresses are formed due to the non-uniform contraction and expansion during the welding process. These stresses can be affected by many parameters like welding parameters and also the geometry of the specimen. To reach the structural integrity of the welded structures, it is necessary to correctly determine the distribution and magnitude of the welding remained stress and also evaluate their effects. During the last decade, a significant progress has been made in the prediction of the residual stresses of different welding processes, and several commercial finite element codes can now handle this issue [1]. Gao et al. studied pass-by-pass stress evolution in multipass welds using Finite Element (FE) technique [2].

*. Corresponding author. Tel.: +98 2188353893 ;

Fax: +982188013029

E-mail addresses: mrfarahani@ut.ac.ir (M.R. Farahani);

setayesh_zargar@ut.ac.ir (S.Hakkak_Zargar);

daakbari@modares.ac.ir (D. Akbari)
Finite element method was also employed to estimate the welding residual stresses of high-strength steels by Yajiang and Juan [3]. Syngellakis and Mellor used asymmetric two-dimensional FE model for analyzing a butt-welded plate [4]. Zhu and Chao studied the effects of the material properties on the finite element modeling of welds [5]. Ramjaun et al. investigated the influence of interpass temperature on residual stresses in multipass welds, considering welding phase transformation [6]. Due to the high significant effects of welding residual stress on the mechanical behavior of the welded structures, some researchers worked on the effects of these stresses on the crack behavior of the structures [7-9].

The welding process parameters and the geometrical properties of the welded joints have a significant effect on the residual stress distribution of the welded structures. The effects of the different welding parameters influencing the remained stresses in welded objects were studied by Peng-Hsiang and TsoLiang [10]. Tso-Liang et al. investigated the effects of the parameters related to the material, such as physical 
and mechanical properties of the base metal and filler metal; geometrical parameters such as weld groove geometry and type of the welding joint; and welding parameters such as the type of the welding process, current, voltage, welding speed on the magnitude, and distribution of the welding remained stresses [11]. The effect of clamping condition on the residual stresses and distortions in a butt-welded plate was studied by Choobi et al. [12]. Akbari et al. investigated the effects of the weld groove shape and geometry on residual stresses in a butt-welded pipe [13]. In a different work, they presented the effects of the welding heat input on residual stresses in butt welds of welded pipe joints [14].

In most published papers, only the welding joints with the simple V-groove shape were considered. Veiga et al. employed the experimental methods to investigate the effects of the weld groove shape in a buttwelded plate [15].

In this paper, distribution of the welding remained stresses in stainless steel plates was investigated using a three-dimensional FE modeling. The finite element results were evaluated with the experimentally measured data resulted from the hole-drilling. Then, the influences of most usual welding groove types, including $\mathrm{V}$-groove, $\mathrm{X}$-groove, and U-grooves, on the distribution and magnitude of remaining stresses were studied.

\section{Theoretical aspects}

Welding residual stresses are calculated in this paper using finite element technique. Theoretical considerations of the thermal and mechanical analyses were described below.

\subsection{Thermal analysis}

During each welding pass, the distribution of the temperature was estimated from the transient thermal model using first order elements. Goldak et al. suggested a double-ellipsoidal model in order to enter the heat induced by welding arc into the weld metal [16]. The heat flux rate in each node of weld metal was estimated using Goldak equation, and then all heat inputs were distributed on those nodes by the determined ratio. The Goldak equation is explained as follows [16]:

- For the front part of the heat source:

$$
q_{f}=\frac{6 \sqrt{3} f_{f} Q}{a b c_{f} \pi \sqrt{\pi}} e^{\left(-3 x^{2} / a^{2}\right)} e^{\left(-3 y^{2} / b^{2}\right)} e^{\left(-3 z^{2} / c^{2}\right)}
$$

- For the rear part of the heat source:

$$
q_{r}=\frac{6 \sqrt{3} f_{r} Q}{a b c_{r} \pi \sqrt{\pi}} e^{\left(-3 x^{2} / a^{2}\right)} e^{\left(-3 y^{2} / b^{2}\right)} e^{\left(-3 z^{2} / c^{2}\right)},
$$

where $x, y$, and $z$ are local coordinates of the double ellipsoidal model. To model the fraction of heat deposition for rear and front parts, $f_{f}$ and $f_{r}$ are set, respectively. Goldak et al. assumed that $f_{f}$ is 1.5 and $f_{r}$ is 0.5 , because the temperature gradient in the front part of the heat source has a higher rate than the rear part, as demonstrated in [11]. The heat source power of the welding process is shown by $Q$. The parameters $a, b$, and $c$ in Eqs. (1a) and (1b) depend on the welding heat source properties.

Radiation and convection are the two types of thermal boundary conditions considered in this model. Convection losses are considered for lower temperature zones far from the weld line, and the radiation loss accounts for high temperature zone near and in the weld line. Eq. (2) explains all temperature-dependent heat transfer coefficient $\left(\mathrm{w} / \mathrm{m}^{2}\right)$ as below:

$$
\left\{\begin{array}{ll}
\alpha_{h}=0.0668 T & \text { for } \quad 0<T<500 \\
\alpha_{h}=0.231 T-82.1 & \text { for } \quad T>500
\end{array}\right\}
$$

where $T\left({ }^{\circ} \mathrm{C}\right)$ is the temperature. Fenggui et al. assumed that above the melting point, heat conductivity is doubled [17]. This assumption was applied to simulate the effect of convective stirring in a molten material.

\subsection{Mechanical analysis}

In the structural analysis, the history of temperature for each node calculated by the transient thermal analysis was applied as a thermal loading into the mechanical analysis. There is not any solid-state phase transformation in the austenitic stainless steel as reported by Zhu et al. [5].

In the welding process, the total strain can be divided into three components as below:

$$
\varepsilon^{*}=\varepsilon^{* e}+\varepsilon^{* p}+\varepsilon^{* t h},
$$

where $\varepsilon^{* e}+\varepsilon^{* p}$ and $\varepsilon^{* t h}$ are elastic, plastic, and thermal strains, respectively. In the welding simulation, results of strains and stresses are accumulated in each stage. Finally, the welding remained stresses can be calculated when the whole model is cooled down. The isotropic bilinear strain hardening with Von Misses yield criterion was considered as the material properties in this simulation.

\section{Experimental investigations}

In order to verify the FE modeling procedure, the experimental investigations are employed. These experimental data are collected from the upper surface of the butt-welded plates.

\subsection{Specimen preparation}

Two pieces of AISI 304 stainless steel plates, with the length of $500 \mathrm{~mm}$, width of $250 \mathrm{~mm}$ and thickness of 


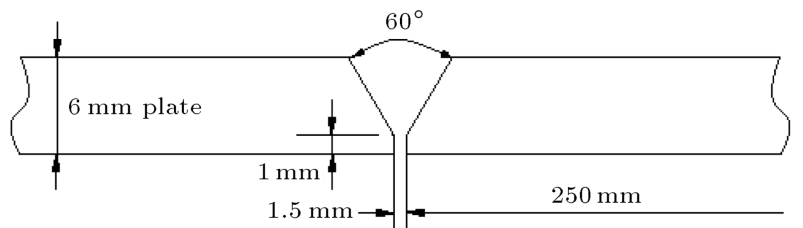

Figure 1. Dimensional details of the specimens used in the experimental studies.

$6 \mathrm{~mm}$, were prepared with V-shape edges. Grade 304 is a standard " $18 / 8$ " stainless steel; it is the most versatile and most widely used stainless steel with excellent welding characteristics. In order to assess the structural integrity of the welded structures from the 304 stainless steel, the mechanical properties of the weld zone must be examined completely [18]. Therefore, investigation on the formation of the residual stress in these joints was carried out in this study. These plates were fitted by utilizing two tack welds at the first and the end of the welding. The dimensions of the prepared welding joint are shown in Figure 1.

An automatic TIG welding machine was used here to carry out the first welding pass. The other passes were done by shielded metal arc welding process. The welding amperage was measured using snap around digital multi-meter. The welding speed was obtained by dividing the weld length into the measured welding time. Table 1 presents the welding parameters of each pass.

Due to the change of the thermal and also mechanical properties by variation in temperature, in this paper, the temperature-dependent material properties for AISI-304 stainless steel were used as reported by Deng and Murakawa [19]. The temperature-dependent material properties are shown in Figure 2.

The filler metals in the different passes are selected, as shown in Table 1. Due to the similarity of mechanical and thermal properties of the base and filler metals, the mechanical and thermal properties were assumed to be the same for both base metal and filler metal in the FEM modeling.

\subsection{Measurement of residual stresses}

The standard method of Hole Drilling Strain-Gauge is used here to measure the remained stresses in the surface of the welded plate. This is an established technique for measuring the residual stress. The ap-

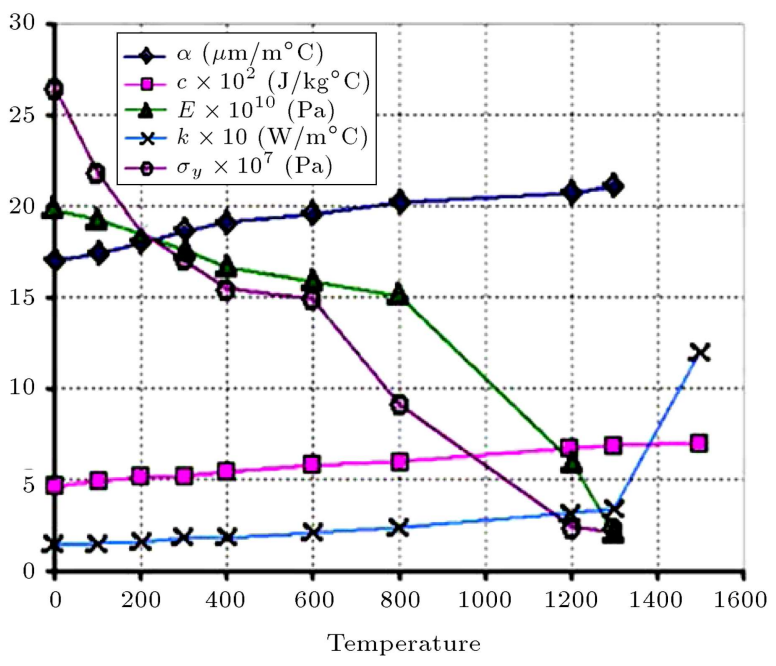

Figure 2. Temperature-dependent material properties of AISI-304 stainless steel.

plication of this method and the method of calculating the residual stresses were discussed in detail in [20]. The released strains were measured after drilling the centre-point of a rosette type gauge by a very highspeed drill. After measuring the released strains by a strain indicator, the longitudinal and traverse residual stresses were calculated according to the following equations based on the ASTM E837-99 standard [21]:

$$
\begin{gathered}
\sigma_{x}=E\left(\varepsilon_{x}+\nu \varepsilon_{y}\right) /\left(1-\nu^{2}\right), \\
\sigma_{y}=E\left(\varepsilon_{y}+\nu \varepsilon_{x}\right) /\left(1-\nu^{2}\right),
\end{gathered}
$$

where $\varepsilon_{x}$ and $\varepsilon_{y}$ are the released strains in the longitudinal and traverse directions, respectively; $E$ is the Young's modulus; and $\nu$ is the Poisson's ratio [20].

The strain gauges of the rosette type (FRS-2-11) were employed in this study. In order to eliminate the effects of starting and completing the welding process, the strain gauges were located in the middle zone of the plate, with minimum $100 \mathrm{~mm}$ away from the plate edges. According to the ASTM standard recommendations, the rosettes should not be very close to each other. So, the rosettes were placed in different paths perpendicular to the weld line. 13 rosettes were mounted on the plate surface at points with $0,1,3$, $6,7,9,11,13,17,23,32,45$, and $60 \mathrm{~mm}$ away from the weld centreline. In Figure 3, the placed rosettes

Table 1. Welding parameters for each pass.

\begin{tabular}{cccccc}
\hline Pass no. & Method & Filler & $\begin{array}{c}\text { Filler diameter } \\
\text { (inch) }\end{array}$ & $\boldsymbol{I}(\mathbf{A})$ & $\begin{array}{c}\text { Velocity } \\
(\mathbf{c m} / \mathbf{m i n})\end{array}$ \\
\hline 1 & TIG & ER 308L & 0.045 & 100 & 2 \\
2 & SMAW & E 308L-16 & $1 / 8$ & 115 & 17 \\
3 & SMAW & E 308L-16 & $1 / 8$ & 115 & 17 \\
4 & SMAW & E 308L-16 & $5 / 32$ & 145 & 19 \\
\hline
\end{tabular}




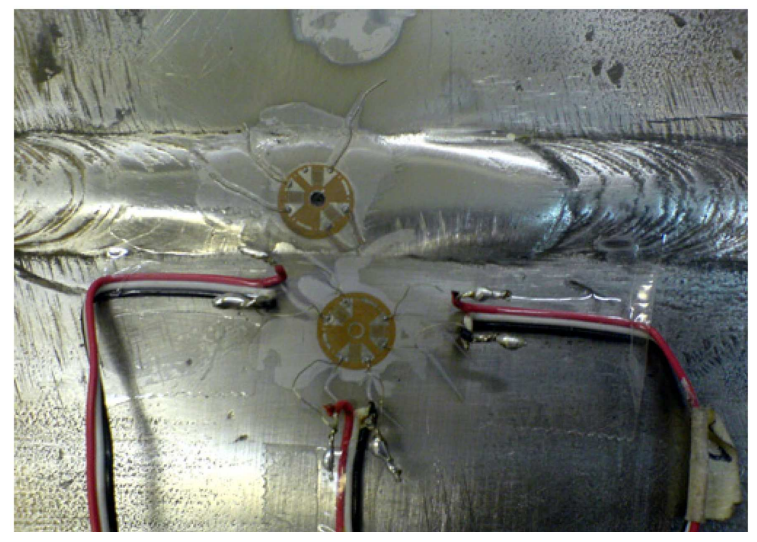

Figure 3. Rosettes placed on the weld centerline and $9 \mathrm{~mm}$ away from the centerline.

on the weld centreline and $9 \mathrm{~mm}$ away from the weld centreline are presented.

\section{Finite element calculations}

\subsection{Welding simulation}

The induced remained stresses of welding processes were determined here by a three-dimensional thermal and structural FE technique. Uncoupled method was used here for calculating the stress field in the welding procedure. It means that at first, a thermal analysis was done to estimate the temperature history of each node, and then its results were entered incrementally as an input load into the structural model to compute the remained stresses [22].

Sattari-Far and Farahani used element birth and death method in the finite element model to model the deposition of the filler metal in the weld groove during the welding [23]. In this method, by multiplying the stiffness of the elements by a severe reduction factor, the elements were deactivated. Then, during the passing of the heat source from each section, the deactivated elements were activated. It should be noted that the speed of the elements' activation has to be the same as the velocity of the electrode movement. One half of the welded plate was modeled, because the welded plates and welding process were symmetrical, and this model required shorter process time. The FE mesh of the welded plates is shown in Figure 4.

\subsection{Discussion on the FEM results}

Welding remained stresses were calculated by the FEM modeling of the butt-welded plate. Along the weld line, a high tensile stress appears near the weld zone and declines by increasing the distance from the weld line. Since the stress distribution in each section of a body should be self-balancing, the compressive remained stress is formed far from the weld zone.

It was observed that the stresses at the starting point of the weld and its proximity were different

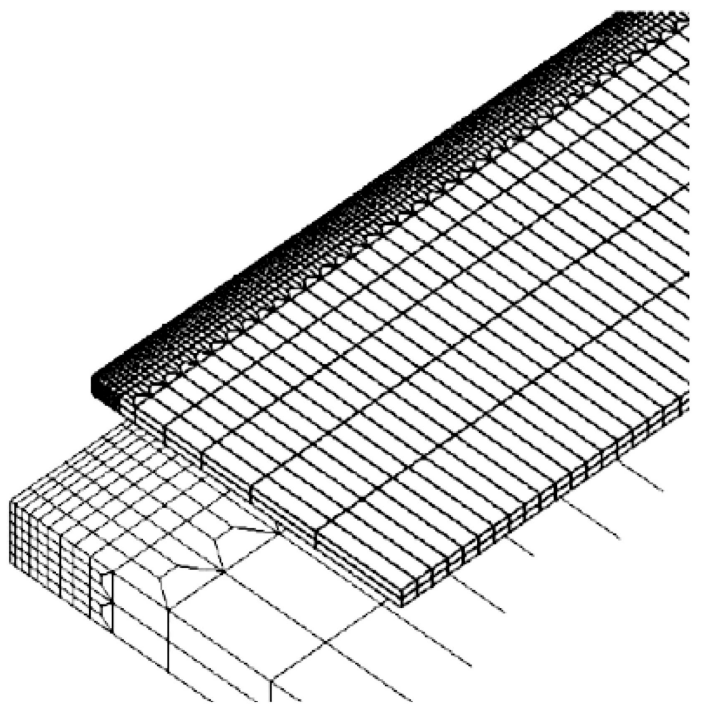

Figure 4. Finite element mesh used for the analysis of butt-welded joints.

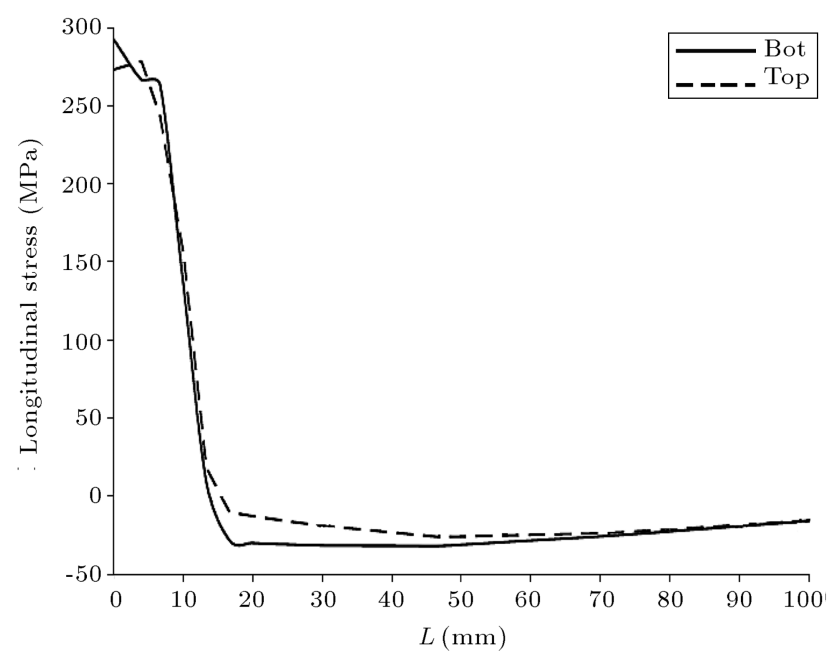

Figure 5. Distribution of the longitudinal residual stresses in the direction perpendicular to the weld line.

from the other locations. In Figures 5 and 6 , the distribution of the longitudinal and traverse remained stresses perpendicular to the weld line on the upper side and lower side of the plate are shown. Small differences between the longitudinal residual stresses on the bottom and top sides of the plate were observed. The large differences between transverse residual stresses on two sides of the plate were presented. These differences can lead to angular deformation of the butt-welded plates.

To validate the results of the FE simulation, a finite element model with the same items with those used in the specimen preparation was generated. On the other side, the residual stresses were measured using hole drilling strain gauge measurement technique in 13 points. Figures 7 and 8 show numerical and experimental results of the longitudinal and traverse 


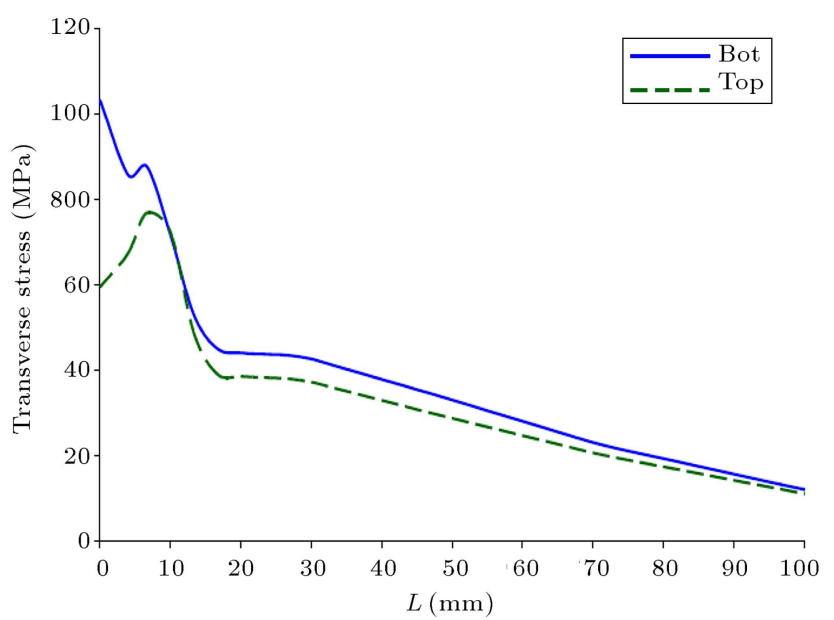

Figure 6. Distribution of the traverse residual stresses in the direction perpendicular to the weld line.

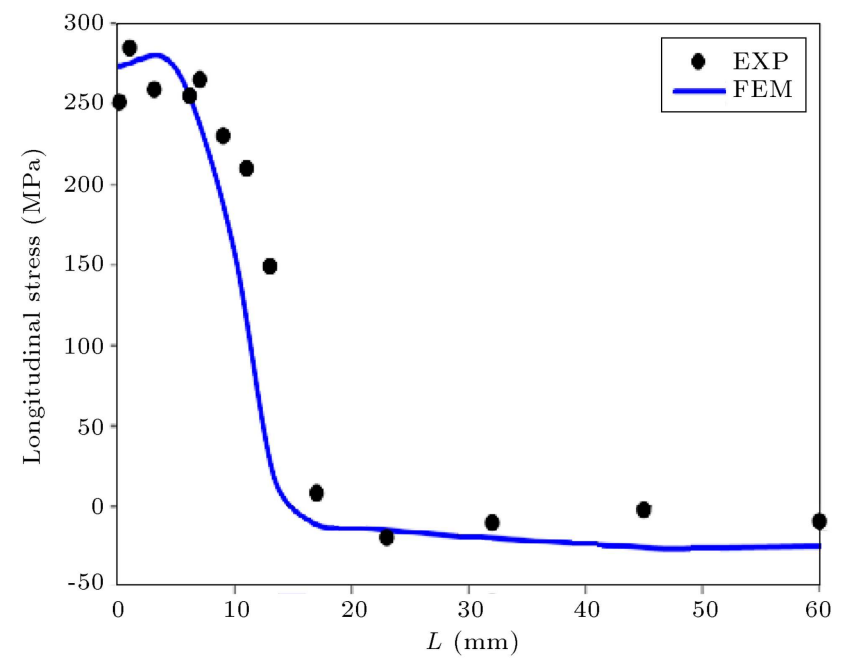

Figure 7. Experimental and analytical results of the longitudinal residual stresses on the upper side of the plate.

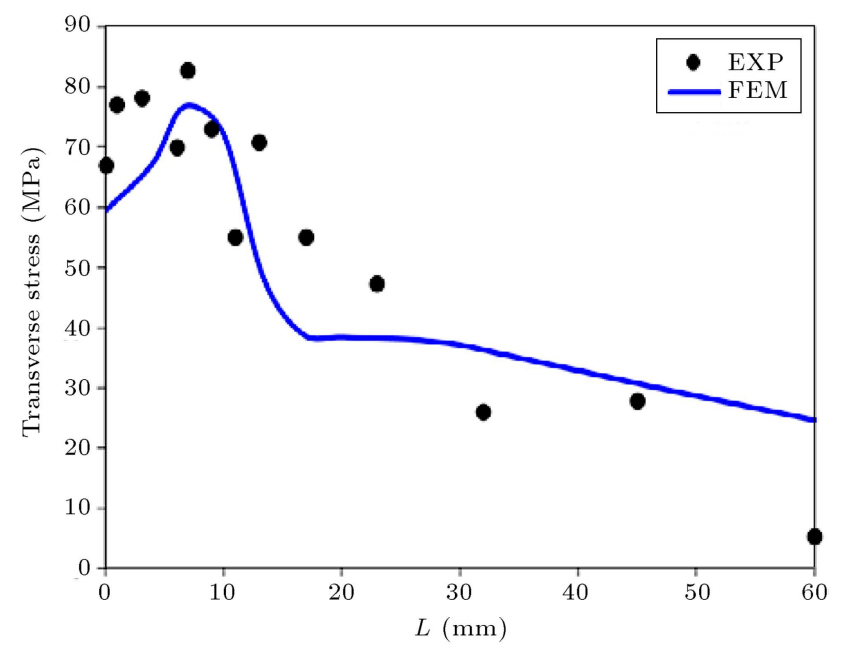

Figure 8. Experimental and analytical results of the traverse residual stresses on the upper side of the plate. residual stresses on the upper side of the plate. Generally, these figures indicate that the results predicted by finite element simulation are relatively compatible with the experimental measurements.

\section{Study of the weld groove shape}

In order to investigate the effects of the weld groove shape on the residual stress distribution, three different weld groove shapes of $\mathrm{V}$-groove, U-groove, and $\mathrm{X}$ groove were investigated in two different plate thicknesses of 6 and 12 millimeters. The magnitude of the heat input was adjusted to have a melted zone as in Figure 1.

\subsection{6-mm thick plate model}

Welded plates of 6-millimeter-thick were investigated by three different groove types of $\mathrm{V}, \mathrm{X}$, and $\mathrm{U}$, as shown in Figure 9.

As a result of the comparison between longitudinal stresses of these three models on the upper and lower sides, it was indicated that at the plate with thickness of $6 \mathrm{~mm}$, the weld groove shape had minor influence on the magnitude of the longitudinal stresses, as can be seen in Figures 10 and 11. An extension in the tensile residual stresses zone was observed for U-groove type weld. This may have resulted from the large hightemperature zone along the welded joint in this type of groove. Also, a difference between the magnitudes of
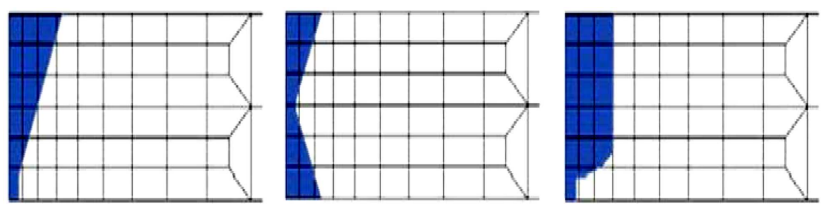

Figure 9. Schematic view of three different weld groove shapes studied here.

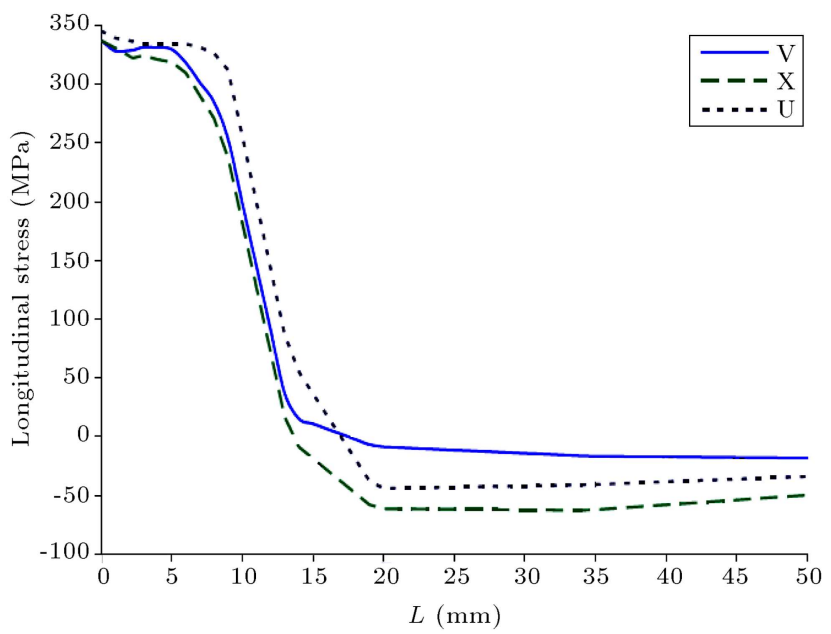

Figure 10. Distribution of longitudinal residual stresses in the direction perpendicular to the weld line on the lower side of the plate. 


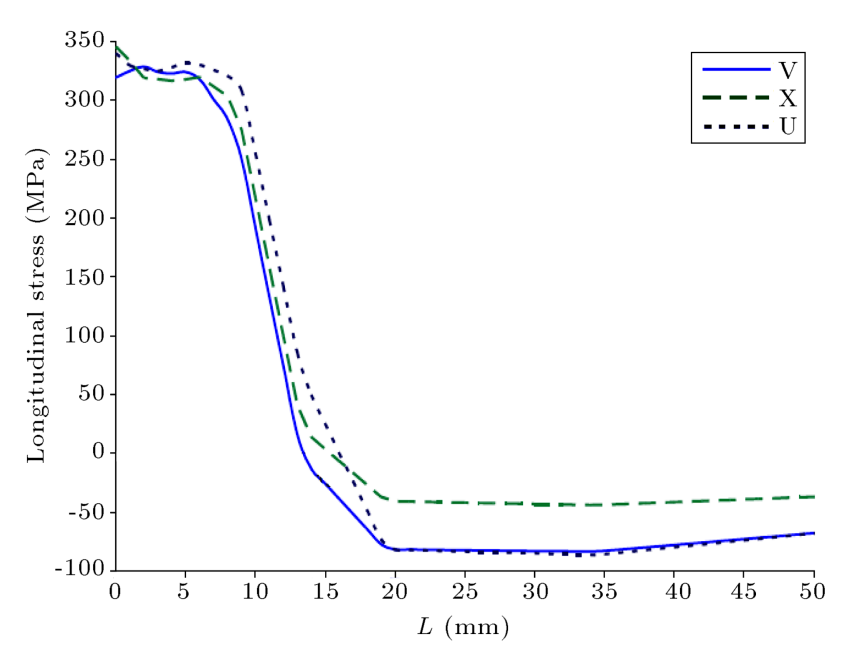

Figure 11. Distribution of longitudinal residual stresses in the direction perpendicular to the weld line on the upper side of the plate.
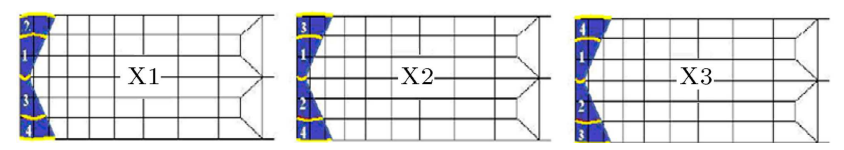

Figure 12. Schematic models of the X1, X2, and X3 grooves.

the compressive residual stresses can be seen far from the welding line.

No significant differences between the transverse residual stresses for these models were observed.

\subsection{2-mm thick plate model}

The effects of the weld groove shape on the residual stresses were studied here for plates of 12-millimeterthick. For these plates, three different welding sequences were studied in the X-groove shape models, as shown in Figure 12.

The distributions of the longitudinal and traverse residual stresses for lower side of the plates are presented in Figures 13 and 14, respectively. The maximum tensile longitudinal stresses were the same for all the cases on the lower side. But, the compressive stresses of X1-, X2-, and X3-groove types were greater than $U$ - and $V$-groove types. It was observed that there were no meaningful differences between the calculated longitudinal residual stress for $X 2$ and $X 3$ models.

As can be seen in Figure 14, the maximum tensile transverse stress for X1- and X2-groove types was greater than that of $\mathrm{U}$ - and V-groove types. Also, the value of these stresses, $10 \mathrm{~mm}$ away from the weld centerline, was the same for all the cases on the lower side of the plates. Again, approximately, the same transverse residual stress for X2 and X3 models was observed. The distribution of the longitudinal stresses on the upper side of the 12-mm-thick plate is shown in Figures 14 and 15. The maximum tensile stresses were the same for all models, while for the welded plates with

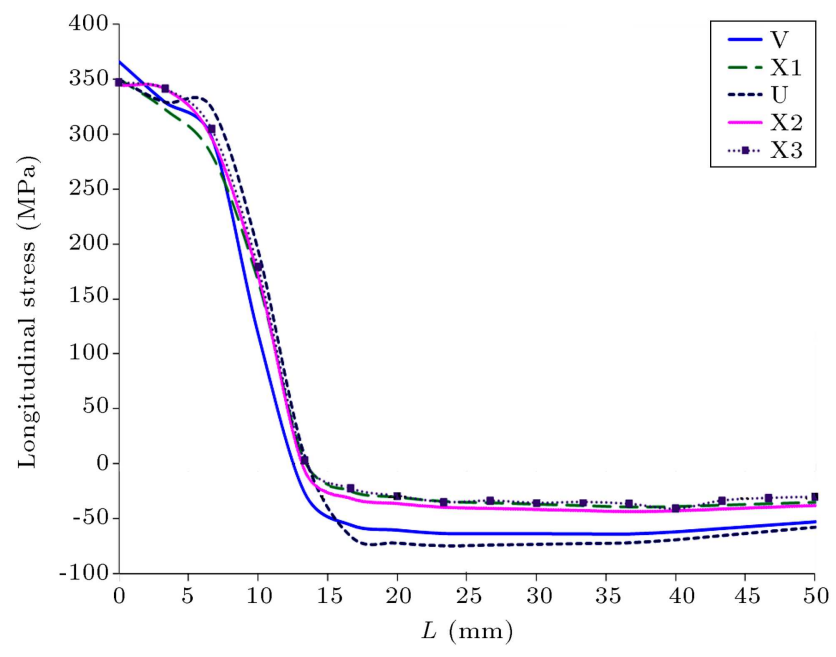

Figure 13. Distribution of the longitudinal residual stresses in the direction perpendicular to the weld line on the lower side of the plate.

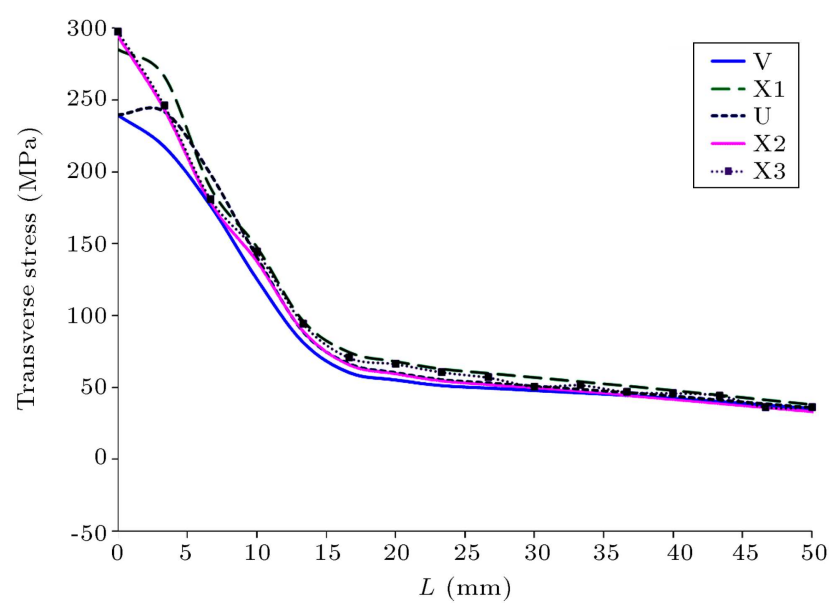

Figure 14. Distribution of the traverse residual stresses in the direction perpendicular to the weld line on the lower side of the plate.

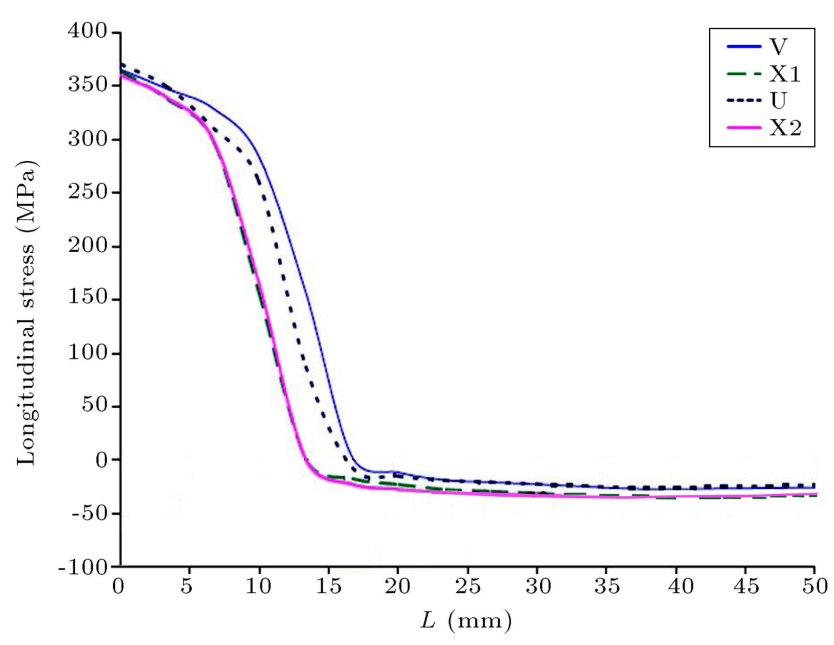

Figure 15. Distribution of the longitudinal stress in the direction perpendicular to the weld line on the upper side of the plate. 


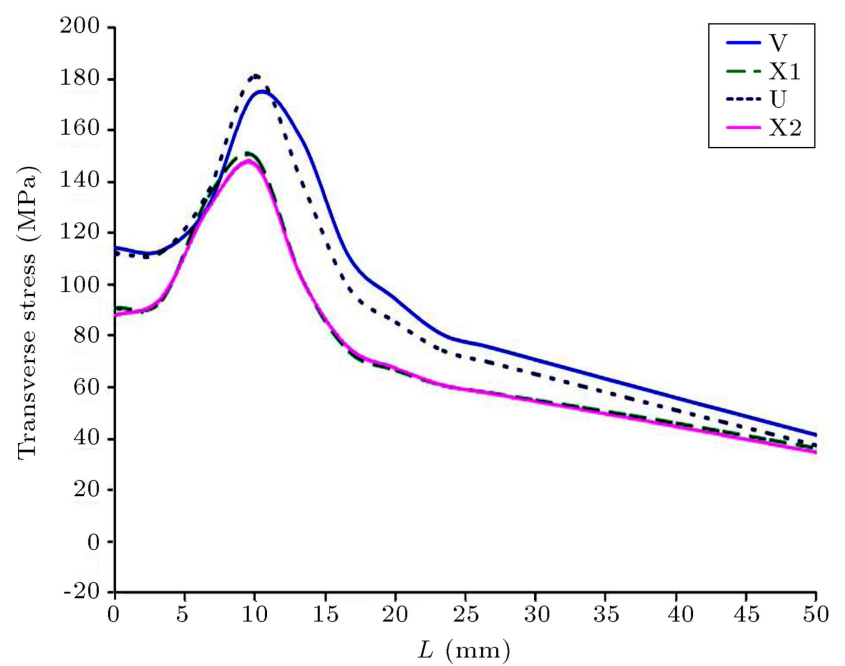

Figure 16. Distribution of the traverse stress in the direction perpendicular to the weld line on the upper side of the plate.

groove shapes of $\mathrm{U}$ and $\mathrm{V}$, the tensile stresses extend more than X-shape models.

According to Figure 16, the maximum tensile residual stresses for $\mathrm{U}$ - and $\mathrm{V}$-groove types were greater than X1 and X2 models. The maximum stress values for all of the cases were observed at $100 \mathrm{~mm}$ away from the weld centerline. The results for X2 and X3 models were the same to a great extent. The results of the X3 model were not presented in Figures 15 and 16.

\section{Conclusion}

In this paper, finite element technique was employed to evaluate the remained stress formation in butt-welded plate joints. By comparison between the experimental measurements and numerical results, it is indicated that the utilized procedure is a suitable technique to predict the welding stresses. Based on this study, the following conclusions may be made:

- In thin plates studied in this investigation $(6 \mathrm{~mm}$ thick), type of the weld groove shape has insignificant influence on the peak of tensile stress on the outer surfaces of the butt-welded joints;

- Compared with other groove types, an extension in the tensile stress zone was observed in the U-shaped groove types;

- In thick welded plates (12 mm thick), the type of groove shape has no significant influence on the peak of longitudinal stresses on the lower side of the plates. But, the extension of the longitudinal residual stresses on the upper side of models with $\mathrm{U}$ - and $\mathrm{V}$-groove types was greater than $\mathrm{X}$-groove models;

- Tensile transverse residual stresses in X1 and X2 models were greater than U- and V-groove types on the lower side of the thick welded plates $(12 \mathrm{~mm}$ thick), but a reverse trend was observed on the upper side.

\section{Acknowledgment}

The authors are grateful for the support of the Iran National Science Foundation (INSF) in Project No. 9100812.

\section{References}

1. Farahani, M. and Sattari-Far, I. "Effects of residual stresses on crack-tip constraints", Scientia Iranica, B, 18(6), pp. 1267-1276 (2011).

2. Gao, H., Dutta, R.K., Huizenga, R.M., Amirthalingam, M., Hermans, M.J.M., Buslaps, T. and Richardson, I.M. "Pass-by-pass stress evolution in multipass welds", Int. J. Sci. Tech. Weld. Join., 19, pp. 256-264 (2014).

3. Yajiang, L., Juan, W., Maoai, C. and Xiaoqin, S. "Finite element analysis of residual stress in the welded zone of a high strength steel", Bull Mater. Sci., 27, pp. 127-132 (2004).

4. Syngellakis, S. and Mellor, B. "Finite element analysis of residual stresses in a but weld", Southampton University of Southampton (1999).

5. Zhu, X. and Chao, Y. "Effects of temperaturedependent material properties on welding simulation", Computers and Structures, 80, pp. 967-976 (2002).

6. Ramjaun, T., Stone, H.J., Karlsson, L., Kelleher, J., Moat, R.J., Kornmeier, J.R., Dalaei, K. and Bhadeshia, H.K.D.H. "Effect of interpass temperature on residual stresses in multipass welds produced using low transformation temperature filler alloy", Int. J. Sci. Tech. Weld. Join., 19, pp. 44-51 (2014).

7. Farahani, M., Sattari-Far, I., Akbari, D. and Alderliesten, R. "Numerical and experimental investigations of effects of residual stresses on crack behavior in Aluminum 6082-T6", Proceedings of the Institution of Mechanical Engineers, Part C: Journal of Mechanical Engineering Science, 226, pp. 2178-2191 (2012).

8. Farahani, M., Sattari-Far, I., Akbari, D. and Alderliesten, R. "Effect of residual stresses on crack behaviour in single edge bending specimens", Fatigue \& Fracture of Engineering Materials \& Structures, 36, pp. 115-126 (2013).

9. Mohammadzadeh Jamalian, H., Farahani, M., Besharati, M.K. and Aghaei, M. "Study on the effects of friction stir welding process parameters on the microstructure and mechanical properties of 5086-H34 aluminum welded joints", The International Journal of Advanced Manufacturing Technology, 83, pp. 611-621 (2016).

10. Peng-Hsiang, C. and Tso-Liang, T. "Numerical and experimental investigations on the residual stresses of 
the butt-welded joints", Comp. Mater. Sci., 29, pp. 511-522 (2004).

11. Tso-Liang, T. and Chih-Cheng, L. "Effect of welding conditions on residual stresses due to butt welds", Int. J. Pressure Vessels and Piping, 75, pp. 857-864 (1998).

12. Choobi, S., Haghpanahi, M. and Sedighi, M. "Investigation of the effect of clamping on residual stresses and distortions in butt welded plates", Scientia Iranica, B, 17(5), pp. 387-394 (2010).

13. Akbari, D., Farahani, M. and Soltani, N. "Effects of the weld groove shape and geometry on residual stresses in dissimilar butt-welded pipes", The Journal of Strain Analysis for Engineering Design, 47, pp. 7382 (2012).

14. Akbari, D. and Sattari-Far, I. "Effect of the welding heat input on residual stresses in butt-welds of dissimilar pipe joints", Int. J. of Pressure Vessels and Piping, 86, pp. 769-776 (2009).

15. Veiga, C., Loureiro, A., Pina, A. and Castarihola Batista, A. "Residual stress distribution in butt welded joints- effect of the weld groove shape", Int. J. Mater. Sci., pp. 387-392 (2002).

16. Goldak, K., Chakaravarti, A. and Bibby, M. "A new finite element model for welding heat sources", Metall. Trans. B, 15B, pp. 299-305 (1984).

17. Fenggui, L., Shun, Y. and Songnian, L. "Modeling and finite element analysis on GTAW arc and weld pool", Comp. Mater. Sci., 29, pp. 371-378 (2004).

18. Sabokrouh, M., Hashemi, H. and Farahani, M.R. "Experimental study of weld microstructure properties in assembling of natural gas transmission pipeline", Proc. IMeche Part B: J. Engineering Manufacture (2015).

19. Deng, D. and Murakawa, H. "Numerical simulation of temperature field and residual stress in multi-pass welds in stainless steel pipe and comparison with experimental measurements", Comp. Mater. Sci., 13, pp. 1690-1701 (2005).

20. Technical note, TN-503 "Measurement of residual stresses by the hole drilling strain gauge method", Measurement Groups Press (1993).
21. ASTM E837-99, Standard Test Method for Determining Residual Stresses by the Hole-Drilling Strain-Gage Method, ASTM International (2001).

22. Zargar, S.H., Farahani, M. and Besharati Givi, M. "Numerical and experimental investigation on the effects of submerged arc welding sequence on the residual distortion of the fillet welded plates", Proceedings of the Institution of Mechanical Engineers. Part B: Journal of Engineering Manufacture, 230, pp. 654-661 (2016).

23. Sattari-Far, I. and Farahani, M.R. "Effect of the weld groove shape and pass number on residual stresses in butt-welded pipes", Int. J. Pressure Vessels and Piping, 86, pp. 723-731 (2009).

\section{Biographies}

Mohammadreza Farahani completed his $\mathrm{PhD}$ degree in Mechanical Engineering in Amirkabir University of Technology, Tehran, Iran. Currently, he is an Assistant Professor in the School of Mechanical Engineering, College of Engineering, University of Tehran. His research interests are Welding mechanics, Nondestructive testing, and Fracture mechanics considering welded structure's fracture behavior.

Setayesh Hakkak Zargar completed his MSc degree in Mechanical Engineering in the School of Mechanical Engineering, College of Engineering, University of Tehran, Tehran, Iran. His research interests are Welding technology, Finite element method, Nondestructive testing, Surface preparing and Coating, and Machining process.

Davood Akbari completed his PhD degree in Mechanical Engineering in the School of Mechanical Engineering, College of Engineering, University of Tehran, Iran. Currently, he is an Assistant Professor in Tarbiat Modarres University. His research interests are welding mechanics and nondestructive testing. 